\title{
Successful Detection of Renal Involvement in Sjögren's Syndrome Secondary to Systemic Lupus Erythematosus by Renal Biopsy
}

\author{
Akira Okada ${ }^{1,2}$, Taiko Yoshida ${ }^{1}$, Koji Takemura ${ }^{1}$, Kazuyoshi Ishigaki $^{3}$, \\ Akira Shimizu ${ }^{4}$ and Hideki Takano ${ }^{1}$
}

\begin{abstract}
An 80-year-old man presented with a mildly decreased renal function and increased anti-double-strandedDNA (anti-dsDNA) antibody levels, and met the diagnostic criteria of the American College of Rheumatology for systemic lupus erythematosus (SLE). However, the incremental increase in creatinine levels and the mild proteinuria were inconsistent with lupus nephritis. We performed a renal biopsy, which revealed interstitial nephritis and minor glomerular abnormalities. Further examinations determined that the renal lesion was due to Sjögren's syndrome secondary to SLE. Following treatment with oral prednisolone, the patient's renal function improved as his anti-dsDNA antibody levels decreased. This case report indicates that renal biopsy should be considered even in elderly individuals when it may assist in the diagnosis, treatment, and prognosis of the patient.
\end{abstract}

Key words: anti-dsDNA antibodies, IgG subclasses, interstitial nephritis, Sjögren's syndrome, systemic lupus erythematosus

(Intern Med 54: 1265-1271, 2015)

(DOI: 10.2169/internalmedicine.54.3525)

\section{Introduction}

Anti-double-stranded-DNA (anti-dsDNA) antibodies are considered to be specific for systemic lupus erythematosus (SLE) (1) and are therefore used in the specific diagnosis of SLE. Patients with diseases other than SLE rarely test positive for anti-dsDNA antibodies. As such, patients presenting with both proteinuria and high levels of anti-dsDNA antibodies are suspected to have lupus nephritis. According to the World Health Organization morphological classification of lupus nephritis, the presence of only interstitial changes, in the absence of glomerular changes, excludes the diagnosis of lupus nephritis (2). While SLE patients can have predominant tubulointerstitial lupus nephritis, characterized by predominant or isolated tubulointerstitial renal damage and minimal glomerular abnormalities, it is quite rare (3). To our knowledge, only 13 cases of predominant tubulointerstitial lupus nephritis have been reported in the English literature (3-14). We herein describe the case of an 80-year-old man who had a mild renal dysfunction with increased antidsDNA antibody levels. A renal biopsy revealed almost no glomerular lesions and it was instrumental in determining his true pathophysiology.

\section{Case Report}

An 80-year-old man with a history of glomerulonephritis in his thirties had been treated on an outpatient basis at our hospital for the management of hypertension and proteinuria since 70 years of age. At this time he was taking medication for hypertension, which was well-controlled. During a follow-up visit, the patient revealed the presence of a photosensitive rash for several years; however arthralgia, Ray-

\footnotetext{
${ }^{1}$ Department of Nephrology, Tokyo Teishin Hospital, Japan, ${ }^{2}$ Divison of Nephrology and Endocrinology, The University of Tokyo Graduate School of Medicine, Japan, ${ }^{3}$ Department of Allergy and Rheumatology, The University of Tokyo Graduate School of Medicine, Japan and ${ }^{4}$ Department of Analytic Human Pathology, Nippon Medical School, Japan

Received for publication June 22, 2014; Accepted for publication September 28, 2014

Correspondence to Dr. Akira Okada, aokada-tky@umin.ac.jp
} 
Table. Laboratory Findings.

\begin{tabular}{|c|c|c|c|}
\hline \multicolumn{2}{|l|}{ Hematology } & \multicolumn{2}{|l|}{ Serology } \\
\hline White blood cells & $4,600 / \mu \mathrm{L}$ & IgG & $2,256 \mathrm{mg} / \mathrm{dL}$ \\
\hline Neutrophils & $53.60 \%$ & IgG4 & $116 \mathrm{mg} / \mathrm{dL}$ \\
\hline Lymphocytes & $38.90 \%$ & $\operatorname{Ig} A$ & $273 \mathrm{mg} / \mathrm{dL}$ \\
\hline Eosinophils & $1.50 \%$ & $\operatorname{IgM}$ & $49 \mathrm{mg} / \mathrm{dL}$ \\
\hline Red blood cells & $3.91 \times 10^{6} / \mu \mathrm{L}$ & $\mathrm{C} 3$ & $53 \mathrm{mg} / \mathrm{dL}$ \\
\hline Hemoglobin & $11.7 \mathrm{~g} / \mathrm{dL}$ & $\mathrm{C} 4$ & $2 \mathrm{mg} / \mathrm{dL}$ \\
\hline Hematocrit & $35.20 \%$ & CH50 & $<14.0 \mathrm{U} / \mathrm{L}$ \\
\hline \multirow[t]{2}{*}{ Platelets } & \multirow[t]{2}{*}{$156 \times 10^{3} / \mu \mathrm{L}$} & Antinuclear antibody & $\begin{array}{l}\times 160, \text { homogenous, and } \\
\text { speckled }\end{array}$ \\
\hline & & Anti-ds-DNA antibody & $29 \mathrm{U} / \mathrm{mL}$ \\
\hline \multicolumn{2}{|l|}{ Blood chemistry } & Anti-Sm antibody & $(-)$ \\
\hline Total protein & $7.5 \mathrm{~g} / \mathrm{dL}$ & Anti-SS-A/Ro antibody & $\times 16$ \\
\hline Albumin & $3.5 \mathrm{~g} / \mathrm{dL}$ & Anti-SS-B/La antibody & $(-)$ \\
\hline Aspartate aminotransferase & $31 \mathrm{U} / \mathrm{L}$ & HBe antigen & $(-)$ \\
\hline Alanine aminotransferase & $15 \mathrm{U} / \mathrm{L}$ & HBs antigen & $(+)$ \\
\hline Sodium & $141.7 \mathrm{mEq} / \mathrm{L}$ & HBs antibody & $(-)$ \\
\hline Potassium & $4.2 \mathrm{mEq} / \mathrm{L}$ & HBV DNA & not detected \\
\hline Chloride & $106.6 \mathrm{mEq} / \mathrm{L}$ & Anti-HCV antibody & $(-)$ \\
\hline Blood urea nitrogen & $27.7 \mathrm{mg} / \mathrm{dL}$ & Cryoglobulin & $(-)$ \\
\hline Creatinine & $1.60 \mathrm{mg} / \mathrm{dL}$ & Soluble Il-2 receptor & $1,170 \mathrm{U} / \mathrm{mL}$ \\
\hline Uric acid & $6.2 \mathrm{mg} / \mathrm{dL}$ & & \\
\hline \multirow[t]{2}{*}{ Total cholesterol } & $132 \mathrm{mg} / \mathrm{dL}$ & \multicolumn{2}{|l|}{ Urinalysis } \\
\hline & & $\mathrm{pH}$ & 7.0 \\
\hline Arterial blood gas analysis & (Room air) & Red blood cell & $1-4 / \mathrm{HPF}$ \\
\hline $\mathrm{pH}$ & 7.33 & White blood cell & $1-4 / \mathrm{HPF}$ \\
\hline $\mathrm{PaCO}_{2}$ & $39 \mathrm{mmHg}$ & Granular cast & $1-4 / 100 \mathrm{LPF}$ \\
\hline $\mathrm{PaO}_{2}$ & $80 \mathrm{mmHg}$ & Epithelial cast & $1-4 / 100 \mathrm{LPF}$ \\
\hline \multirow[t]{3}{*}{ Bicarbonate } & $20.6 \mathrm{mmol} / \mathrm{L}$ & beta2-Microglobulin & $7,423 \mathrm{ng} / \mathrm{mL}$ \\
\hline & & $\mathrm{N}$-acetyl-beta-D-glucosaminidase & $17.1 \mathrm{U} / \mathrm{L}(16.7 \mathrm{U} / \mathrm{gCr})$ \\
\hline & & U-Protein/U-Creatinine & $1.09 \mathrm{~g} / \mathrm{gCr}$ \\
\hline
\end{tabular}

naud's phenomenon, rash, oral ulcers, and alopecia were absent. Serological tests undertaken during an outpatient visit revealed high titers of antinuclear antibodies (ANA) and anti-dsDNA antibodies, low complement levels, and a mild decline in renal function. The laboratory data change did not seem to affect urinary protein levels, which fluctuated between 0.3 and $1.3 \mathrm{~g} / \mathrm{gCr}$, irrespective of the levels of serum creatinine and anti-dsDNA antibodies. According to the clinical symptoms and laboratory data, the patient fulfilled the American College of Rheumatology (ACR) criteria for SLE (photosensitivity, ANA positivity, anti-DNA antibody positivity, and a renal disorder). Based on these findings, we initially suspected the patient to have lupus nephritis; however, his proteinuria was inconsistent with his renal dysfunction, thus suggesting another pathophysiology was present. We therefore decided to perform a renal biopsy to clarify the underlying pathophysiology.

The laboratory data collected at the time of hospital admission are shown in Table. Urinalysis revealed mild proteinuria $(0.26 \mathrm{~g} / \mathrm{gCr})$ with an estimated creatinine clearance (Cockcroft-Gault equation) of $32 \mathrm{~mL} / \mathrm{min}$. The urinary sediments were significant for only 1-4 granular casts/100 low power field, and urine biochemistry analysis showed elevated levels of $\mathrm{N}$-acetyl-beta-D-glucosaminidase (16.7 U/ $\mathrm{gCr}$ ). Hematological exams revealed anemia (two occasions of lymphopenia were present before treatment). Blood chemistry tests showed increased levels of blood urea nitrogen and serum creatinine $(27.7 \mathrm{mg} / \mathrm{dL}$ and $1.60 \mathrm{mg} / \mathrm{dL}$, respectively), but no abnormalities in electrolytes, such as hypokalemia, were observed. An arterial blood gas analysis revealed mild metabolic acidosis with a slightly elevated anion gap (pH 7.33, $\mathrm{PaCO}_{2} 40 \mathrm{mmHg}$, bicarbonate $20.6 \mathrm{mmol} / \mathrm{L}$, anion gap 14.5). Serological studies revealed an elevated ANA titer $(\times 160$, homogeneous and speckled) and an increased anti-dsDNA antibody level $(54 \mathrm{IU} / \mathrm{mL})$. The serum levels of complement component 3 (C3), complement component $4(\mathrm{C} 4)$, and $50 \%$ hemolytic complement unit (CH50) were $53 \mathrm{mg} / \mathrm{dL}, 2.0 \mathrm{mg} / \mathrm{dL}$, and $<14.0 \mathrm{U} / \mathrm{L}$, respectively. The anti-SS-A/Ro test was positive, but tests for the anti-SS$\mathrm{B} / \mathrm{La}$ antibody, anti-myeloperoxidase anti-neutrophil cytoplasmic antibody, anti-proteinase 3 anti-neutrophil cytoplasmic antibody and anti-glomerular basement membrane antibody were negative. The patient was positive for serum hepatitis B surface antigen (HBsAg), but DNA copies of the hepatitis B virus (HBV) were not detected in the blood. Tests for the anti-hepatitis $\mathrm{C}$ virus antibodies and antihuman immunodeficiency virus antibodies were negative. The serum cryoglobulin was not detected.

Following these laboratory findings, the patient was admitted to our hospital for renal biopsy. Physical examination 


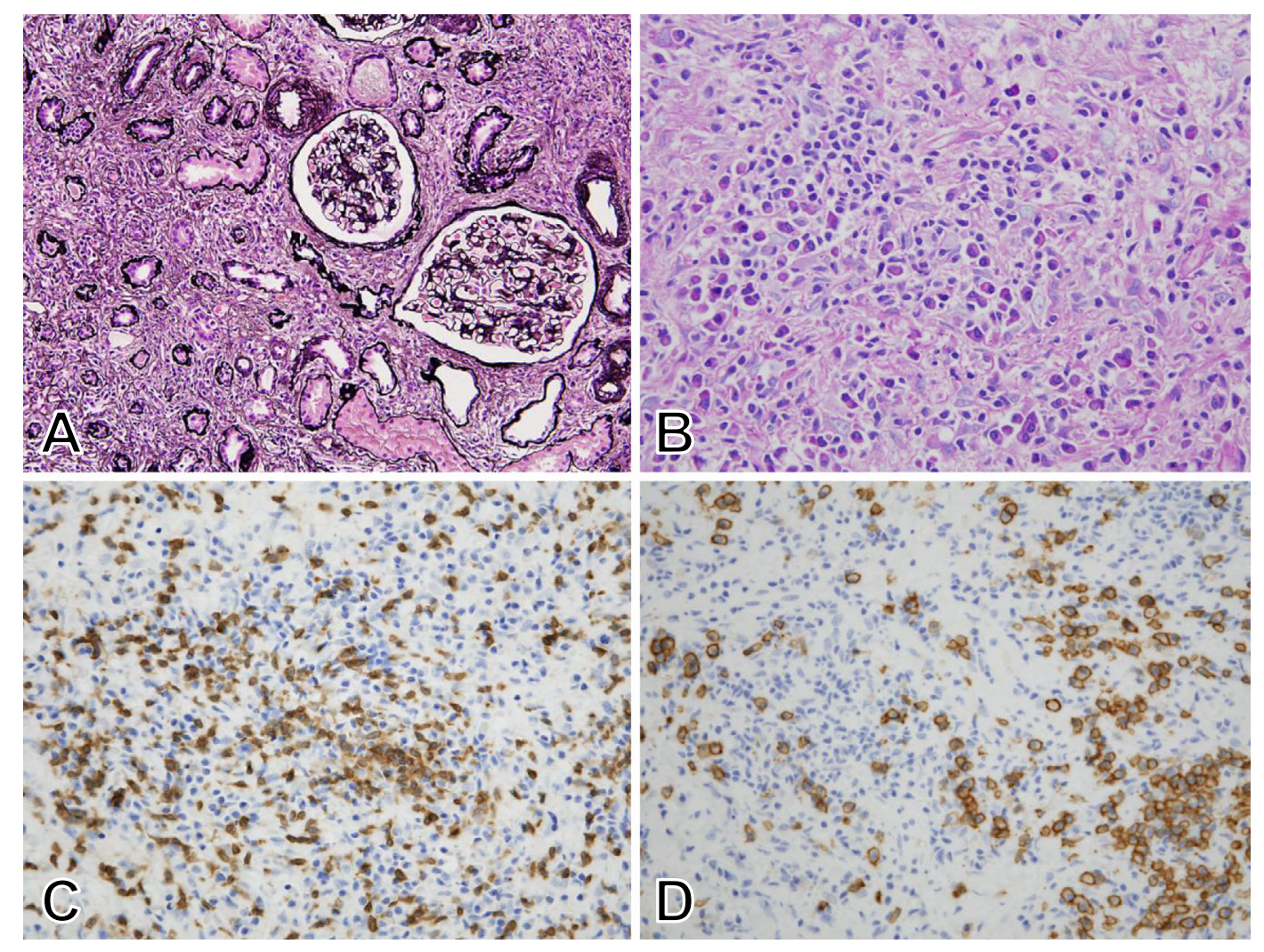

Figure 1. Light microscopic findings of renal biopsy. Light microscopy findings showed almost intact glomeruli and diffuse tubulointerstitial nephritis. (A) Tubulointerstitial nephritis developed; however, glomeruli showed minor glomerular abnormalities (periodic acid-silver methenamine stain; original magnification $\times \mathbf{3 0 0}$ ). (B) Large numbers of inflammatory cells, including abundant plasmacytes, infiltrated the tubulointerstitial areas (periodic acid-Schiff stain; original magnification $\times 600$ ). (C, D) Infiltrating cells included large numbers of $\mathrm{CD3}+\mathrm{T}$ cells $(\mathrm{C})$ and $\mathrm{CD38}+$ plasmacytes (D) (original magnification $\times \mathbf{6 0 0}$ ).

showed that the patient's blood pressure was $128 / 53 \mathrm{mmHg}$, his pulse was $75 / \mathrm{min}$ with a regular rhythm, and his body temperature was $36.3^{\circ} \mathrm{C}$. No abnormalities were detected in the patient's lungs, heart or abdomen. There was no purpura seen, but slight pitting edema of the lower legs was observed. No abnormalities were found on the chest X-ray, electrocardiogram, or abdominal ultrasonogram findings. A percutaneous renal biopsy was performed on the day of admission, and two kidney punctures were performed. The procedure did not result in any serious complications, such as a massive hemorrhage requiring transfusion.

Light microscopy determined that the two renal specimens contained eight glomeruli in total. Minor glomerular abnormalities were found in six of the eight glomeruli. The remaining two glomeruli were obsolescent, with severe arteriosclerosis characterized by a marked fibrous intimal thickening, and mild arteriolar hyalinosis. In contrast, the interstitium was found to be diffusely infiltrated by lymphocytes and plasma cells. Granulomas were not detected in the tubulointerstitium. Tubular atrophy and diffuse fibrosis were also observed (Fig. 1A, B). Immunostaining for $\mathrm{CD} 3+\mathrm{T}$ cells, CD20+ B cells, and CD38+ plasma cells suggested that the majority of the cells in the infiltrate were $\mathrm{T}$ cells, plasma cells, and a few B cells (Fig. 1C, D). Based on staining for the kappa-chains and lambda-chains, monoclonal proliferation was unlikely. Additionally, only a few of the infiltrating plasma cells were IgG4 positive (data not shown), thus the underlying pathology was unlikely to be malignant lymphoma, IgG4-related disease, or sarcoidosis. Immunofluorescence microscopy showed positive staining with fine granular distribution for $\mathrm{IgG}$ and $\mathrm{Clq}$ in the tubular basement membrane (TBM), but not in the glomerulus (Fig. 2A). Electron microscopy revealed small dense deposits in the TBM (Fig. 2B). Thus, histopathologically, the decline in renal function was considered to be due to chronic plasma cell-rich interstitial nephritis and minor glomerular abnormalities.

We next tried to elucidate the pathophysiology underlying the interstitial nephritis. Gallium scintigraphy was unremarkable for malignant lymphoma or sarcoidosis, and the soluble IL-2 receptor level of $1,170 \mathrm{U} / \mathrm{mL}$ indicated that lymphoproliferative diseases were an unlikely possibility. Schirmer's tear test, gum test, and fluorescein leakage test all showed positive findings. Additionally, consistent with the renal pathology, his lip biopsy revealed a significant infiltration of lymphocyte and plasma cells without any kappa and lambda chain monoclonality. (Fig. 3). Collectively, these patient symptoms and clinical findings met the ACR criteria for 

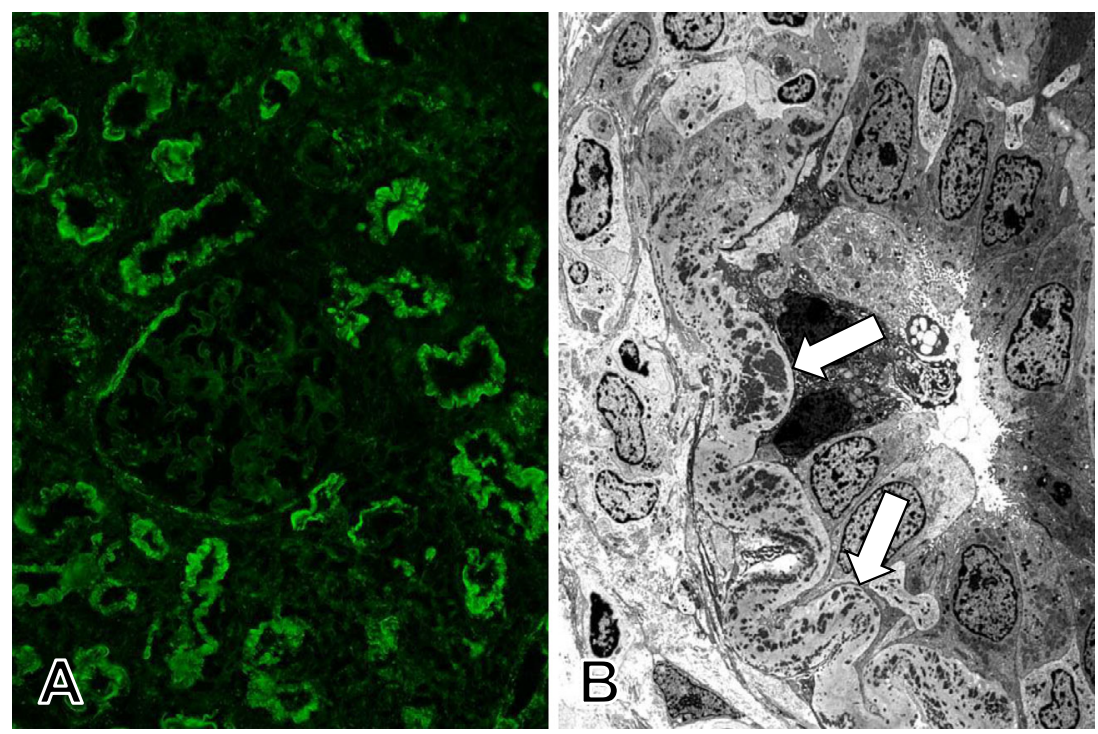

Figure 2. Immunofluorescence staining and electron microscopy of the renal biopsy. (A) Immunofluorescence staining for IgG showed positive staining along the tubular basement membrane, but no obvious deposition in the glomeruli (original magnification $\times \mathbf{2 0 0}$ ). (B) Electron microscopy revealed no electron-dense deposits in the glomeruli, and small electron-dense deposits (arrows in $B$ ) in the tubular basement membrane (original magnification: $\times \mathbf{1 0 , 0 0 0 )}$.
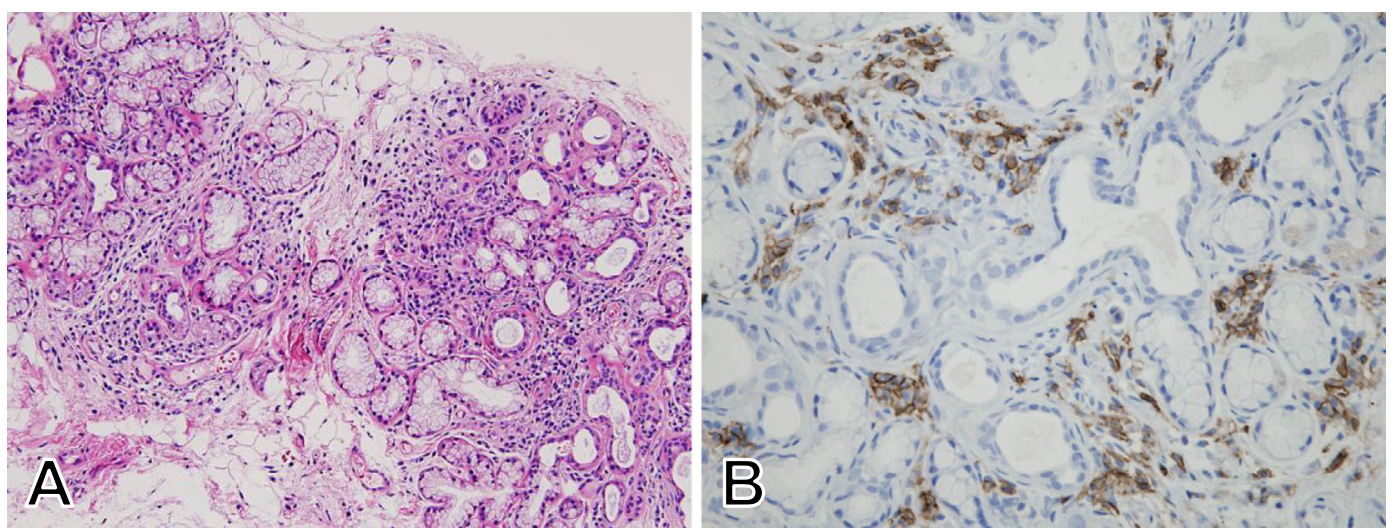

Figure 3. Light microscopic findings of salivary gland biopsy. (A) Infiltration of mononuclear cells was observed near interlobular ducts (Hematoxylin and Eosin staining; original magnification, $\times$ 400). (B) Immunostaining for CD38+ plasmacytes revealed that the infiltrating cells in the salivary gland included large numbers of CD38+ plasmacytes, in a manner similar to that in the tubulointerstitial nephritis (original magnification, $\times \mathbf{6 0 0}$ ).

Sjögren's syndrome (SS) (positive serum anti-SS-A/Ro antibody, ocular findings, and presence of focal lymphocytic sialadenitis). Since the renal pathological findings showed chronic plasma cell-rich interstitial nephritis without glomerulonephritis, we concluded that the renal lesion resulted from secondary SS associated with SLE rather than predominant tubulointerstitial nephritis associated with SLE alone.

Oral prednisolone treatment of $30 \mathrm{mg} /$ day $(0.5 \mathrm{mg} / \mathrm{kg} /$ day) was started immediately for the renal involvement in SS. Since the patient was positive for HBsAg before treatment, HBV DNA levels were monitored; however, none was detected. The patient's clinical course is shown in Fig. 4. After several weeks, the patient's renal function, anti-
dsDNA antibody, and C3 levels began to improve, but the proteinuria did not change. Due to the possibility of HBV reactivation, the prednisolone dose was tapered. Several weeks after prednisolone initiation, the patient's serum creatinine level decreased from 1.6 to $1.1 \mathrm{mg} / \mathrm{dL}$; however, the proteinuria did not improve, while the complement and antidsDNA antibody values remained well-controlled.

\section{Discussion}

Our patient met the criteria of SLE, and was considered to have lupus nephritis owing to the characteristic high serum creatinine levels and proteinuria. Likewise, most clinicians would assume that his renal pathology should be lupus 


\section{PSL $30 \mathrm{mg} /$ day started}

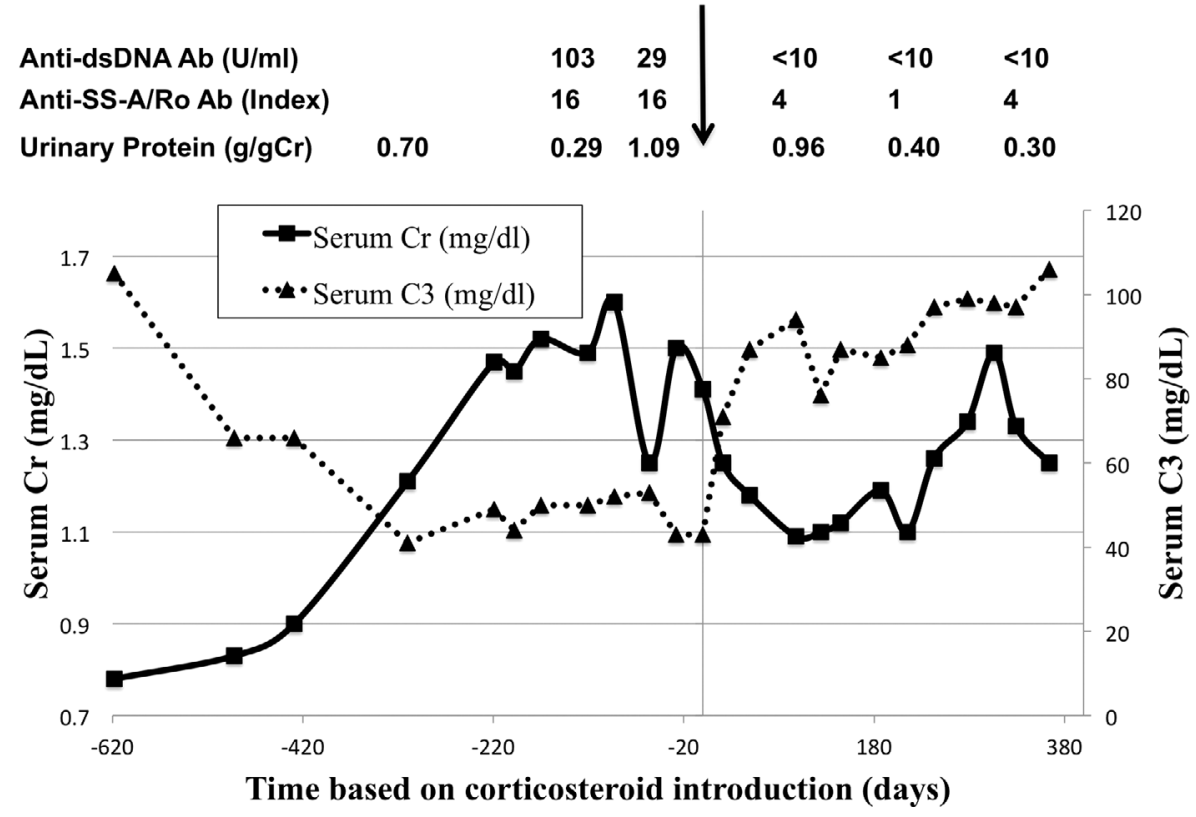

Figure 4. Patient's clinical course. Ab: antibody, Cr: creatinine, PSL: prednisolone

nephritis without renal biopsy because of the presence of proteinuria and the diagnosis of SLE. Approximately twothirds of lupus nephritis patients have tubulointerstitial involvement $(15,16)$; however, most cases show glomerular lesions in contrast to our patient. Glomerular abnormalities are necessary for the diagnosis of lupus nephritis, according to the International Society of Nephrology classification of lupus nephritis in 2003 (2), therefore, further investigation into the etiology of our patient was thus considered to be necessary.

The patient's renal biopsy showed chronic plasma cellrich tubulointerstitial nephritis, minor abnormalities in the glomeruli, and arteriosclerosis. The pathology findings indicated that there was chronic renal injury due to the lymphocytes and plasma cells in the interstitial infiltrate and to the global arteriosclerosis-associated glomeruloscleroses observed in two out of the eight glomeruli examined. This chronic injury resulted in a gradual decline in the renal function. Six of the eight glomeruli were almost intact, indicating that there was little possibility of primary or secondary glomerulonephritis. The global sclerosis observed in the two glomeruli was most likely caused by hypertensive nephropathy that was associated with the mild proteinuria. Due to the risk of procedural complications, we performed only two punctures at the time of the renal biopsy, which provided a specimen containing a total of eight glomeruli.

It was necessary to rule out any other secondary causes for the interstitial nephritis. Our patient had no history of recent infections, exposure to nephrotoxic agents, or exposure to radiation, and a lack of eosinophils in the interstitial infiltrate ruled out an underlying allergic pathology. In addition, sarcoidosis was unlikely owing to the lack of any interstitial granulomatous lesions in the renal pathology of our patient, and the Gallium scintigram findings did not support sarcoidosis. However, the pathological findings of the tubulointerstitium assisted in making a differential diagnosis. First, we used staining for IgG subclasses to exclude IgG4-related diseases. Although the patient met the ACR criteria for SLE, he also met the ACR criteria for SS (positive serum anti-SSA/Ro antibody, ocular findings, and the presence of focal lymphocytic sialadenitis) (17). However, despite the diagnosis of SS, the patient did not display distal renal tubular acidosis (RTA). His urinary $\mathrm{pH}$ ranged between 5.0 and 7.0, the serum potassium values were not low, and a hyperchloremic metabolic acidosis was not observed. However, mild metabolic acidosis with a mildly elevated anion gap was present, which was attributed to the decline in the estimated creatinine clearance. Patients with distal RTA do not typically have a urinary $\mathrm{pH}$ below 5.5, although a urinary $\mathrm{pH}$ $<5.5$ has been reported (18). Furthermore, he did not exhibit extraglandular symptoms of SS in any other organs besides the kidneys, such as respiratory, musculoskeletal or gastrointestinal symptoms.

We next tried to clearly delineate whether the pathological origin of the renal lesion was attributed to the SLE or was secondary SS associated with SLE. However, both predominant tubulointerstitial lupus nephritis and SS-associated nephropathy can present with mononuclear infiltration and deposits in the TBM, thus making it extremely difficult to distinguish between them pathologically $(11,19,20)$. The chronic plasma cell-rich inflammation indicated that the types and distributions of the infiltrated cells in the renal salivary gland lesions were similar. Hence, we suspected that the etiology was more likely nephropathy due to SS. There has been no previous report noting a C1q deposition in the TBM in primary SS. However, Clq deposition in the 
TBM is a feature associated with tubulointerstitial lupus nephritis, and is therefore not contradictory with secondary SS-associated SLE. Despite the 13 case reports of predominant tubulointerstitial lupus nephritis, the other symptoms were associated with SS rather than SLE, thus supporting our diagnosis. As such, the detailed examinations and the resulting pathological findings were instrumental in making an accurate differential diagnosis in this case.

SLE is deeply related to SS, and both are often diagnosed in the same patient (21). The clinical profiles of patients with both SS and SLE are more similar to those of patients with primary SS alone, than to those of patients with SLE alone (22). Compared with the patients with SLE alone, patients with both SLE and SS were significantly older, had a higher frequency of anti-SS-A/Ro, anti-SS-B/La and antidsDNA antibodies, and had a significantly lower frequency of renal involvement (23). SS-onset lupus patients have distinctive clinical manifestations and a benign prognosis (24). Graninger et al. proposed the hypothesis that simultaneous primary SS with SLE is the prevailing factor leading to the rare occurrence of isolated interstitial nephritis in SLE, but the rare occurrence of this condition prevented a consensus from being reached (25).

Our patient displayed increased anti-dsDNA antibodies and hypocomplementemia, which are typically suggestive of SLE. However, although the active phase of SLE is commonly characterized by hypocomplementemia, about $12 \%$ of SS cases also present with hypocomplementemia, which in SS is associated with increased mortality (26), and thus careful attention was needed for the patient during followup. In addition, hypocomplementemia is sometimes observed in SLE-associated SS. However, the patient's symptoms of SLE were mild, and secondary SS is ordinarily milder than the primary disease. Additionally, the renal lesion showed a good response to the moderate administration of corticosteroids, which is consistent with a report by Mori et al. that suggested that patients with predominant tubulointerstitial lupus nephritis responded well to moderate doses of corticosteroids alone (3), thereby indicating the therapeutic response was not a definitive factor. Furthermore, the improvement in serum complement and antidsDNA antibody levels was associated with a decrease in the serum creatinine levels. Nevertheless, based on the patient's clinical history, physical examination and pathology findings, we considered it more reasonable to attribute the renal damage to SLE-associated secondary SS rather than SLE alone.

While the indications for renal biopsy have been previously discussed, no absolute criteria exist. In chronic kidney disease (CKD), the kidney dimension is considered the major determinant before renal biopsy (27). Risk factors for the development of erythrocyte transfusion after a renal biopsy are known to be age, blood pressure, serum creatinine levels and hemoglobin levels (28). In Japan, where the elderly have accounted for $>20 \%$ of the population since 2005 according to the national population census by the Ministry of
Internal Affairs and Communications, healthcare maintenance in the elderly is crucial. Due to the aging population, the importance of renal biopsy in CKD management is increasing in the field of nephrology. Age is primarily taken into consideration because of potential complications such as decreased quality of life and hemorrhage. While physicians must carefully consider the potential complications associated with a renal biopsy in elderly individuals, renal biopsy should thus not be precluded if it could potentially have a positive impact on the patient's treatment and prognosis.

Although the herein described case appears to be the 14th case of predominant tubulointerstitial lupus nephritis, our findings indicate it is actually a case of renal involvement in SS secondary to SLE in which all renal findings were due to SS and not SLE. While the renal biopsy in the present case displayed similar features to the previously-reported tubulointerstitial lupus nephritis cases, the similar features in the exocrine glands were clearly related to SS, rather than SLE. The renal biopsy led to an accurate diagnosis, and thus prevented the unnecessary immunosuppressive therapy of a very elderly patient. Similar to the present case, renal biopsy should therefore be considered in elderly individuals when it may affect the diagnosis, treatment, and patient prognosis.

\section{The authors state that they have no Conflict of Interest (COI).}

\section{References}

1. Avina-Zubieta JA, Galindo-Rodriguez G, Kwan-Yeung L, Davis P, Russell AS. Clinical evaluation of various selected ELISA kits for the detection of anti-DNA antibodies. Lupus 4: 370-374, 1995.

2. Weening JJ, D'Agati VD, Schwartz MM, et al. The classification of glomerulonephritis in systemic lupus erythematosus revisited. J Am Soc Nephrol 15: 241-250, 2004.

3. Mori Y, Kishimoto N, Yamahara H, et al. Predominant tubulointerstitial nephritis in a patient with systemic lupus nephritis. Clin Exp Nephrol 9: 79-84, 2005.

4. Case records of the Massachusetts General Hospital. Weekly clinicopathological exercises. Case 2-1976. N Engl J Med 294: 100105, 1976.

5. Disler PB, Lewin JR, Laidley L, Meyers AM. Systemic lupus erythematosus with pure interstitial disease: a case report [abstract]. Kidney Int 13: 428, 1978.

6. Cunningham E, Provost T, Brentjens J, Reichlin M, Venuto RC. Acute renal failure secondary to interstitial lupus nephritis. Arch Intern Med 138: 1560-1561, 1978.

7. Tron F, Ganeval D, Droz D. Immunologically-mediated acute renal failure of nonglomerular origin in the course of systemic lupus erythematosus [SLE]. Report of two cases. Am J Med 67: 529532, 1979.

8. Klahr S. Interstitial nephritis in a patient with systemic lupus erythematosus. Am J Med 69: 775-781, 1980.

9. Makker SP. Tubular basement membrane antibody-induced interstitial nephritis in systemic lupus erythematosus. Am J Med 69: 949-952, 1980.

10. Gur H, Kopolovic Y, Gross DJ. Chronic predominant interstitial nephritis in a patient with systemic lupus erythematosus: a follow up of three years and review of the literature. Ann Rheum Dis 46: 617-623, 1987.

11. Singh AK, Ucci A, Madias NE. Predominant tubulointerstitial lu- 
pus nephritis. Am J Kidney Dis 27: 273-278, 1996.

12. Michail S, Stathakis C, Marinaki S, Revenas C, Nakopoulou L, Vaiopoulos G. Relapse of predominant tubulointerstitial lupus nephritis. Lupus 12: 728-729, 2003.

13. Omokawa A, Wakui H, Okuyama S, et al. Predominant tubulointerstitial nephritis in a patient with systemic lupus erythematosus: phenotype of infiltrating cells. Clin Nephrol 69: 436-444, 2008.

14. Ali A, Al-Windawi S. Tubulointerstitial lupus nephritis. J Nephropathol 2: 75-80, 2013.

15. Park MH, D'Agati V, Appel GB, Pirani CL. Tubulointerstitial disease in lupus nephritis: relationship to immune deposits, interstitial inflammation, glomerular changes, renal function, and prognosis. Nephron 44: 309-319, 1986.

16. Brentjens JR, Sepulveda $M$, Baliah $T$, et al. Interstitial immune complex nephritis in patients with systemic lupus erythematosus. Kidney Int 7: 342-350, 1975.

17. Shiboski SC, Shiboski CH, Criswell L, et al. American College of Rheumatology classification criteria for Sjögren's syndrome: a data-driven, expert consensus approach in the Sjögren's International Collaborative Clinical Alliance cohort. Arthritis Care Res (Hoboken) 64: 475-487, 2012.

18. Kim S, Lee JW, Park J, et al. The urine-blood PCO gradient as a diagnostic index of $\mathrm{H}(+)$-ATPase defect distal renal tubular acidosis. Kidney Int 66: 761-767, 2004.

19. Kronbichler A, Mayer G. Renal involvement in autoimmune connective tissue diseases. BMC Med 11: 95, 2013.

20. Winer RL, Cohen AH, Sawhney AS, Gorman JT. Sjögren's syndrome with immune-complex tubulointerstitial renal disease. Clin Immunol Immunopathol 8: 494-503, 1977.
21. Szanto A, Szodoray P, Kiss E, Kapitany A, Szegedi G, Zeher M. Clinical, serologic, and genetic profiles of patients with associated Sjögren's syndrome and systemic lupus erythematosus. Hum Immunol 67: 924-930, 2006.

22. Manoussakis MN, Georgopoulou C, Zintzaras E, et al. Sjögren's syndrome associated with systemic lupus erythematosus: clinical and laboratory profiles and comparison with primary Sjögren's syndrome. Arthritis Rheum 50: 882-891, 2004.

23. Pan HF, Ye DQ, Wang Q, et al. Clinical and laboratory profiles of systemic lupus erythematosus associated with Sjögren syndrome in China: a study of 542 patients. Clin Rheumatol 27: 339-343, 2008.

24. Xu D, Tian X, Zhang W, Zhang X, Liu B, Zhang F. Sjögren's syndrome-onset lupus patients have distinctive clinical manifestations and benign prognosis: a case-control study. Lupus 19: 197200, 2010.

25. Graninger WB, Steinberg AD, Meron G, Smolen JS. Interstitial nephritis in patients with systemic lupus erythematosus: a manifestation of concomitant Sjögren's syndrome? Clin Exp Rheumatol 9: 41-45, 1991

26. Garcia-Carrasco M, Mendoza-Pinto C, Jimenez-Hernandez C, Jimenez-Hernandez M, Nava-Zavala A, Riebeling C. Serologic features of primary Sjögren's syndrome: clinical and prognostic correlation. Int J Clin Rheumtol 7: 651-659, 2012.

27. Fuiano G, Mazza G, Comi N, et al. Current indications for renal biopsy: a questionnaire-based survey. Am J Kidney Dis 35: 448457, 2000.

28. Corapi KM, Chen JL, Balk EM, Gordon CE. Bleeding complications of native kidney biopsy: a systematic review and metaanalysis. Am J Kidney Dis 60: 62-73, 2012.

(C) 2015 The Japanese Society of Internal Medicine http://www.naika.or.jp/imonline/index.html 